\title{
Band 3 Profile as a Marker of Erythrocyte Changes in Chronic Kidney Disease Patients
}

\author{
Elísio Costa ${ }^{1,2,3}$, Susana Rocha ${ }^{2,3}$, Petronila Rocha-Pereira, ${ }^{3,4}$, Elisabeth Castro ${ }^{2,3}$, Vasco Miranda ${ }^{5}$, \\ Maria do Sameiro Faria ${ }^{5}$, Alfredo Loureiro ${ }^{6}$, Alexandre Quintanilha, ${ }^{3,7}$ Luís Belo ${ }^{2,3}$ and Alice \\ Santos-Silva ${ }^{2,3}$
}

${ }^{I}$ Instituto de Ciências da Saúde, Universidade Católica Portuguesa; ${ }^{2}$ Faculdade de Farmácia da Universidade do Porto; ${ }^{3}$ Instituto de Biologia Molecular e Celular da Universidade do Porto (IBMC); ${ }^{4}$ Centro Investigação Ciências Saúde, Universidade Beira Interior, Covilhã; ${ }^{5} F M C$, Dinefro - Diálises e Nefrologia, SA; ${ }^{6}$ Uninefro - Sociedade Prestadora de Cuidados Médicos e de Diálise, SA and ${ }^{7}$ Instituto de Ciências Biomédicas Abel Salazar da Universidade do Porto (ICBAS)

\begin{abstract}
Our aim was to study changes in red blood cell (RBC) membrane band 3 profile, as a cumulative marker of $\mathrm{RBC}$ changes, in chronic kidney disease (CKD) patients under haemodialysis and recombinant human erythropoietin (rhEPO) therapy and its linkage with resistance to this therapy.

We studied 63 CKD patients, 32 responders and 31 non-responders to rhEPO therapy, and 26 healthy individuals. We evaluated the band 3 profile [\% of band 3 monomer, high molecular weight aggregates (HMWAg), and proteolytic fragments (Pfrag)], membrane-bound haemoglobin (MBH), haematological data, total serum bilirubin, glutathione peroxidase (GPx) and superoxide dismutase activities, total antioxidant status (TAS) and plasma lipid peroxidation (TBA). Compared to controls, band 3 profile presented by CKD patients showed statistically significant lower HMWAg and Pfrag values and a significant higher value in band 3 monomer. GPx, TBA and TAS activities, and TBA/TAS ratio were also significantly higher in CKD patients. Comparing responders to non-responders CKD patients, significantly lower value in Pfrag and a trend for a higher value in $\mathrm{MBH}$ were found in non-responders.

Our data suggest that CKD patients present younger RBC population, which could be related to the rhEPO therapy. The adverse plasma environment associated to CKD patients under hemodialysis imposes changes in band 3 profile, particularly in non-responders, suggesting that resistance to rhEPO therapy in CKD patients seems to be associated to an increase in RBC damage.
\end{abstract}

Key-Words: Band 3 protein; Membrane bound haemoglobin; oxidative stress, RBC, Haemodialysis, Resitance to rhEPO therapy.

\section{INTRODUCTION}

Haemodialysis increases longevity of patients with endstage renal disease by removing the metabolic end products and excess of water. Despite the technologic developments of haemodialysis procedures and of medical support in the last years, the morbidity and mortality of these patients remain high, about 10 to 20 times higher than that found in general population [1-3]. Anaemia is a frequent complication associated with chronic kidney disease (CKD), and is mainly due to insufficient erythropoietin renal production.

Until 18 years ago, the treatment of anaemia of CKD was blood transfusion; however, the management of this anaemia has been improved by the introduction of recombinant human EPO (rhEPO) therapy. This therapy allowed a significant reduction in the associated adverse effects of anaemia and improved patient's quality of life. There is, however, a

*Address correspondence to this author at the Serviço de Bioquímica, Faculdade de Farmácia da Universidade do Porto, Rua Aníbal Cunha, 164, 4099-030 Porto, Portugal; E-mail: elisio_costa@hotmail.com marked variability in the sensitivity to rhEPO, with up to 10 fold variability in dose requirements to achieve correction of the anaemia [4-10].

Although oxygen is essential to human life, paradoxically, it can also cause great harm via oxidation/reduction reactions and formation of reactive oxygen species (ROS). Oxidative stress and its related biological effects have a pathologic relevance in many disease states, namely, in those having an associated inflammatory component [6-8]. There are increasing evidence that ROS are involved in the progression of renal damage and uraemic symptoms. The oxidative stress appears to be multifactorial and is thought to be caused only in part by the impaired kidney function [6-8]. The several factors that have been implicated in the development of oxidative stress in CKD patients undergoing haemodialysis include the haemodialysis procedure, uraemia, inflammation, disturbances in iron homeostasis, and reduction in the antioxidant defence systems. The later includes enzymatic systems involved in red blood cell (RBC) antioxidant defence, such as superoxide dismutase (SOD) and glutathione peroxidase (GPx). These enzymes are impor- 
tant to maintain higher levels of reduced glutathione, which is important in detoxifying the cell from ROS, and, therefore, in protecting the cell from their deleterious effects. Most of these factors are described also as independent factors of resistance to rhEPO therapy, particularly inflammation [11$15]$.

The RBC, presenting a limited biosynthesis capacity, suffers and accumulates physical and/or chemical changes, which become more pronounced with cell aging, and whenever an unusual physical or chemical stress develops [16]. RBCs that develop intracellular defects earlier during their life span are removed prematurely from circulation [16-20]. The removal of senescent or damaged RBCs seems to involve the binding of a senescent neoantigen the RBC membrane surface, marking the cell for death. This neoantigen is immunologically related to band 3 , a RBC transmembrane protein [18]. The degradation of the RBC metabolism and/or of its antioxidant defences may lead to the development of oxidative stress within the cell, allowing oxidation of haemoglobin $(\mathrm{Hb})$ and its linkage to the cytoplasmatic domain of band 3, promoting its aggregation. This aggregation conditioned the binding of natural antiband 3 autoantibodies and complement activation, marking $\mathrm{RBC}$ for death.

An abnormal band 3 profile [high molecular weight aggregates (HMWAg), band 3 monomer, and proteolytic fragments (Pfrag)], has been associated to younger, damage and/or senescence RBCs. Older and damaged RBCs presented higher band 3 aggregation and lower fragmentation. The younger RBCs showed reduced aggregation and higher fragmentation [16-20].

Our aim was to study RBC damage and oxidative stress status occurring in CKD patients under haemodialysis and rhEPO therapy. The study was performed in a healthy control group and in two groups of CKD patients (responders and non-responders). Some of the CKD patients were also evaluated before and immediately after haemodialysis to study the effect of the dialysis procedure per se. We performed a basic RBC study, by evaluating RBC count, $\mathrm{Hb}$ concentration, haematocrit $(\mathrm{Ht})$ and the haematimetric indexes; the band 3 profile was evaluated as a cumulative marker of RBC damage; reticulocyte count, reticulocyte production index (RPI) and bilirubin levels, as markers of RBC production/removal; SOD and GPx activities, as markers of RBC antioxidant capacity; membrane bound $\mathrm{Hb}(\mathrm{MBH})$, as a marker of oxidative $\mathrm{Hb}$ damage; plasma total antioxidant status (TAS) and lipidic peroxidation (TBA), as well as the ratio TBA/TAS were studied to evaluate the oxidative stress in the plasma $\mathrm{RBC}$ environment.

\section{MATERIAL AND METHODS}

\section{Subjects}

We studied 89 individuals including 63 CKD patients, 32 responders and 31 non-responders to rhEPO therapy, and 26 healthy controls. The rhEPO maintenance dose for responder's patients was $90 \pm 58 \mathrm{U} / \mathrm{Kg} /$ week and for nonresponders was $573 \pm 194 \mathrm{U} / \mathrm{Kg} /$ week. The two groups of patients were matched for age, gender, weight, body mass index, mean time under haemodialysis, urea reduction ratio, urea Ktv and parathyroid hormone serum levels.
No analytical indicators of iron deficiency and/or vitamin B12 and folate deficiencies were found in CKD patients and controls (data not shown).

The causes of renal failure in patient's population were as follows: diabetic nephropathy $(n=19)$, chronic glomerulonephritis $(n=11)$, polycystic kidney disease $(n=3)$, hypertensive nephrosclerosis $(n=3)$, obstructive nephropathy $(\mathrm{n}=3)$, pyelonephritis associated with neurogenic bladder $(n=1)$, nephrolithiasis $(n=1)$, chronic interstitial nephritis $(n=1)$, Alport syndrome $(n=1)$, renal vascular disease due to polyarteritis $(n=1)$ and chronic renal failure of uncertain aetiology $(n=19)$.

Patients with autoimmune diseases, malignancies, haematological disorders, inflammatory disorders and acute or chronic infections, were excluded. All subjects gave their informed consent to participate in this study. Classification of CKD patients as responders or non-responders was performed in accordance with the European Best Practice Guidelines [21] that defines resistance to rhEPO as a failure to achieve target $\mathrm{Hb}$ levels (11-12 $\mathrm{g} / \mathrm{dL})$ with doses of epoetin more than $300 \mathrm{U} / \mathrm{Kg} /$ week or $1.5 \mathrm{mg} / \mathrm{Kg} /$ week of darbopoietin-alfa.

Age and gender-matched individuals, with normal haematological and biochemical values, without any history of renal or inflammatory diseases were used as controls.

\section{ASSAYS}

\section{Blood Samples}

Blood samples were collected from CKD patients before starting haemodialysis. In 20 of the CKD patients (10 responders and 10 non-responders to rhEPO therapy), blood samples were also collected immediately after the dialysis session.

Blood samples were collected with and without EDTA as anticoagulant, in order to obtain whole blood and serum. Whole blood was used for hematological procedures. To access GPx and SOD activities, whole blood and isolated and washed RBC aliquots, respectively, were made and stored at $-70^{\circ} \mathrm{C}$, until assayed. Plasma and serum aliquots were also made and stored at $-70^{\circ} \mathrm{C}$, until assayed.

\section{Haematological and Biochemical Studies}

RBC count, $\mathrm{Ht}, \mathrm{Hb}$ concentration, haematimetric indices [mean cell volume $(\mathrm{MCV})$, mean cell $\mathrm{Hb}(\mathrm{MCH})$ and mean cell $\mathrm{Hb}$ concentration $(\mathrm{MCHC})]$ and red cell distribution width (RDW) were measured by using an automatic blood cell counter (Sysmex K1000; Sysmex, Hamburg, Germany).

Reticulocyte count was performed by microscopic counting on blood smears, after vital staining with New methylene blue (reticulocyte stain; Sigma, St Louis, MO, USA). The reticulocyte production index (RPI) was calculated as an appropriate way to measure the effective RBC production, by considering both changes in $\mathrm{Ht}$ (degree of anaemia) and in the premature reticulocyte release from the bone marrow [22].

Erythrocyte GPx and SOD activities were evaluated by using commercially available kits (RANSEL and RANSOD, 
Randox, UK, respectively). Total antioxidant status (TAS) was evaluated in serum by a commercial colorimetric assay (TAS, Randox). Plasma lipidic peroxidation was estimated by TBA assay [23]. Moreover, the ratio TBA/TAS was evaluated.

Serum total bilirubin levels were evaluated in an autoanalyser (Cobas Mira S, Roche), using a commercially available kit (Bilirubin total, ABX Diagnostics). Serum Creactive protein (CRP) was determined by immunoturbidimetry (CRP latex HS Roche kit, Roche Diagnostics).

\section{Preparation of Erythrocyte Membranes}

Plasma and white blood cells were isolated from RBCs and discarded after centrifugation on a double density gradient (Histopaque 1.077 and 1.119, Sigma). RBCs were washed in saline, and immediately lysed, according to Dodge method [24]. The membranes were carefully washed in Dodge buffer (the first two washes used phenylmethylsulfonyl fluoride, a protease inhibitor, at a final concentration of $0.1 \mu \mathrm{M})$. Protein concentration of the membrane suspensions was determined [25].

\section{Membrane-Bound Hb (MBH)}

MBH was measured spectrophotometrically at $415 \mathrm{~nm}$, after protein dissociation with Triton X-100 (5\% in Dodge buffer). The background was read at $700 \mathrm{~nm}$ to correct the absorbance at $415 \mathrm{~nm}$; the obtained value and the protein concentration were used to estimate the percentage of MBH.

\section{Band 3 Profile}

RBC membranes were treated with an equal volume of a

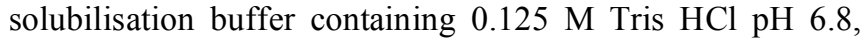
$4 \%$ sodium dodecil sulphate (SDS), $20 \%$ glycerol, and $10 \%$ 2-mercaptoethanol, heat-denatured and submitted to polyacrylamide gel electrophoresis (SDS-PAGE) $(20 \mu \mathrm{g}$ protein/lane), using the discontinuous Laemmli system [26] (a 9\% separating gel and a $4.5 \%$ stacking gel). Membrane proteins were electrophoretically transferred from gels to a nitrocellulose sheet with a porosity of $0.2 \mu \mathrm{m}$ (Sigma) [27]. Additional reactive sites on the nitrocellulose were blocked by incubation in $5 \%$ of low fat dry milk and $0.1 \%$ Triton-X

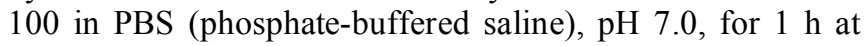
room temperature and under gentle rotation. Band 3 immunoblot was performed [18]; monoclonal antibodies antihuman band 3 , produced in mouse, recognizing an epitope located in the cytoplasmic pole of the band 3 molecule [28] (Sigma), were added (dilution 1:3000) and incubated for $4 \mathrm{~h}$; the washing of the nitrocellulose was followed by the addition and incubation with antimouse $\mathrm{Ig}$ peroxidase linked (Sigma) for $1 \mathrm{~h}$ (dilution 1:4000). The incubations were carried out at room temperature; the dilutions of the antibodies were prepared with PBS $\mathrm{pH} 7.0$ containing $0.1 \%$ Triton-X 100 and $5 \%$ of low fat dry milk. In the washes, the same buffer without dry milk was used. Hydrogen peroxide and $\alpha$-cloronaphtol were used to develop the immunoblot. The band 3 profile was quantified by densitometry (Bio1D++ version 99; Vilber Lourmat, France). We evaluated the percentage of HMWAg, of band 3 monomer and of Pfrag.

\section{DATA ANALYSIS}

Statistical analyses were carried out using the Statistical Package for Social Sciences (SPSS). Multiple comparisons between groups were performed by one-way ANOVA supplemented with Tukey's honestly significant difference (HSD) post hoc test. For data not normally distributed, differences between the three groups were evaluated by the Kruskal-Wallis test; for single comparisons (two groups), the Mann-Whitney $U$ test was used. To assess the influence of the haemodialysis procedure per se on the evaluated parameters, paired t-test or Wilcoxon test were used. Significance was accepted at $p$ less than 0.05 .

Diabetic patients have been associated to an increased oxidative stress $[29,30]$. To exclude this possible confounding factor we further analysed the results, by performing statistical analysis with and without exclusion of the 19 CKD patients with a diabetic nephropathy.

\section{RESULTS}

The results were analysed in order to study the differences between healthy controls and CKD patients; to study the differences between responders and non-responders CKD patients (cross-sectional study), and to study changes imposed by the haemodialysis procedure.

We found that most of the CKD patients (all patients $v s$ controls) presented anaemia with significantly lower RBC count $\left(3.68 \pm 0.54 \times 10^{12} / \mathrm{L}\right.$ vs $\left.4.72 \pm 0.5910^{12} / \mathrm{L}, \mathrm{p}<0.05\right)$, $\mathrm{Hb}[10.90 \mathrm{~g} / \mathrm{dL}(10.30-12.30 \mathrm{~g} / \mathrm{dL})$ vs $13.90 \mathrm{~g} / \mathrm{dL}(13.20-$ $15.00 \mathrm{~g} / \mathrm{dL}), \mathrm{p}<0.05)]$ and $\mathrm{Ht}[34.20 \%(30.60-37.10 \%) v \mathrm{~s}$ $43.10 \%(40.10-46.70 \%), \mathrm{p}<0.05)]$; higher reticulocyte count $\left(61.03 \pm 31.36 \times 10^{9} / \mathrm{L}\right.$ vs $\left.33.57 \pm 22.7810^{9} / \mathrm{L}, \mathrm{p}<0.05\right)$, RPI $[0.98(0.58-1.40)$ vs $0.42(0.19-0.66), \mathrm{p}<0.05)]$ and RDW $(15.92 \pm 2.56 \%$ vs $12.79 \pm 0.52 \%, \mathrm{p}<0.05)$ values were also observed. CKD patients showed (Fig. 1) statistically significant lower HMWAg [15.23 \% (13.38-19.40 \%) vs $19.90 \%$ $(15.42-21.12 \%), \mathrm{p}<0.05)]$ and Pfrag $(22.70 \pm 6.01 \%$ vs 26.29 $\pm 4.78 \%, \mathrm{p}<0.05)$ values, and higher Band 3 monomer values [61.84 \% (56.87-64.41\%) vs 55.28\% (53.39-57.41\%), $\mathrm{p}<0.05)]$. The ratios HMWAg/band 3 monomer $(0.27 \pm 0.07$ vs $0.33 \pm 0.07, \mathrm{p}<0.05)$ and $\mathrm{Pfrag} / \mathrm{band} 3$ monomer $(0.38 \pm$ 0.13 vs $0.48 \pm 0.13, \mathrm{p}<0.05)$ were also lower. GPx activity $(45.82 \pm 13.69 \mathrm{IU} / \mathrm{g} \mathrm{Hb}$ vs $35.62 \pm 8.83 \mathrm{IU} / \mathrm{g} \mathrm{Hb}, \mathrm{p}<0.05)$, TBA $\left(1.49 \pm 0.31 \times 10^{-3} \mathrm{mmol} / \mathrm{L}\right.$ vs $0.84 \pm 0.27 \times 10^{-3} \mathrm{mmol} / \mathrm{L}$ $\mathrm{p}<0.05)$, TAS $(1.79 \pm 0.24 \mathrm{mmol} / \mathrm{L} v s 1.41 \pm 0.29 \mathrm{mmol} / \mathrm{L}$, $\mathrm{p}<0.05)$ and CRP levels $[5.76 \mathrm{mg} / \mathrm{dL}(1.90-14.01 \mathrm{mg} / \mathrm{dL})$ vs $1.75 \mathrm{mg} / \mathrm{dL}(0.76-4.70 \mathrm{mg} / \mathrm{dL}), \mathrm{p}<0.05)]$, and TBA/TAS ratio $(0.85 \pm 0.18$ vs $0.60 \pm 0.28, \mathrm{p}<0.05)$ were higher in CKD patients. Similar values for the activity of SOD and for $\mathrm{MBH}$, between controls and patients, were observed.

In Table 1, we present the haematological data, for controls and CKD patients. When comparing the haematological data between the two groups of CKD patients, we found that non-responders patients were all anaemic and showed significantly lower values of $\mathrm{Hb}$ and $\mathrm{Ht}$; their RBCs were more hypocromic, as reflected by the significantly lower values of $\mathrm{MCH}$ and MCHC; a significantly higher RDW was also observed (Table 1). Statistically significant decreases in Pfrag and in the Pfrag/band 3 monomer ratio, and increase CRP were also found in non-responders CKD patients (Table 2). 
A

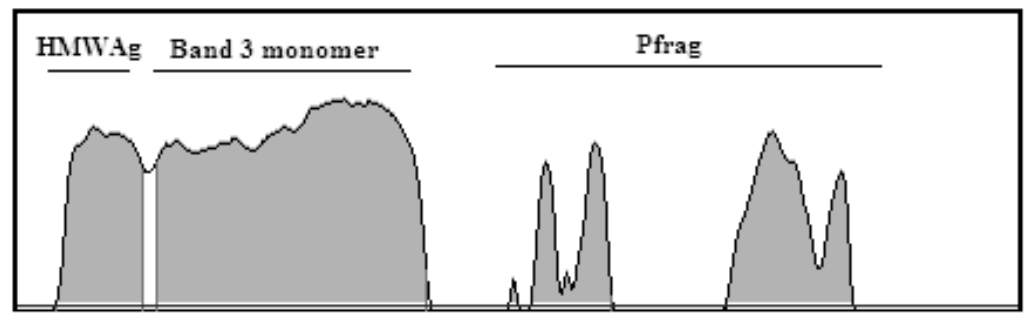

B

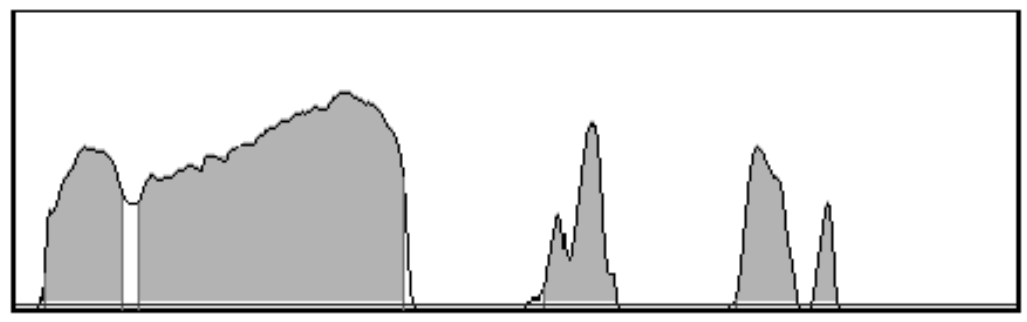

$\mathrm{C}$

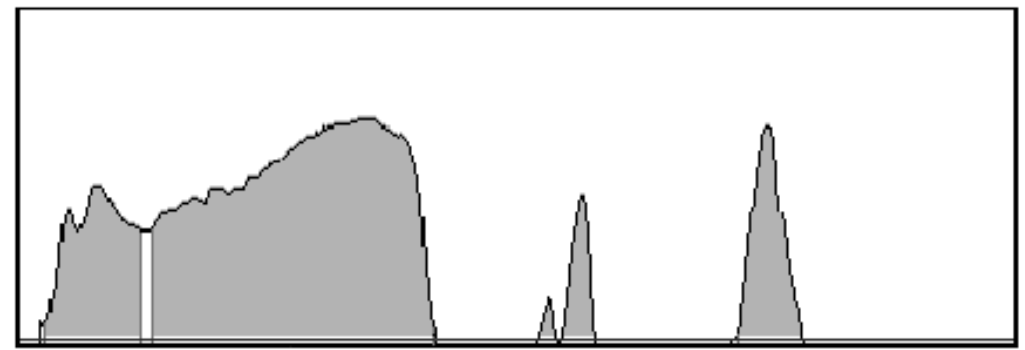

Fig. (1). Examples of densitometer tracing of immunoblots for band 3 profile. A- Control; B- Responder patient; C- Non-responder patient.

Table 1. Haematological Data for Controls and CKD Patients Under Haemodialysis and rhEPO Therapies

\begin{tabular}{|c|c|c|c|}
\hline & $\begin{array}{c}\text { Controls } \\
(\mathbf{n = 2 6})\end{array}$ & $\begin{array}{c}\text { Responders } \\
(\mathbf{n}=\mathbf{3 2})\end{array}$ & $\begin{array}{c}\text { Non-Responders } \\
(\mathbf{n}=\mathbf{3 1})\end{array}$ \\
\hline \hline $\mathrm{Hb}(\mathrm{g} / \mathrm{dL})$ & $13.90(13.2-15.00)$ & $11.70(10.83-12.68) *$ & $10.4(9.00-11.30) * \S$ \\
\hline Haematocrit $(\%)$ & $43.10(40.10-46.70)$ & $35.15(32.25-38.35) *$ & $31.10(27.70-35.20) * \S$ \\
\hline $\mathrm{RBC}\left(\mathrm{x} 10^{12} / \mathrm{L}\right)$ & $4.72 \pm 0.59$ & $3.76 \pm 0.42 \mathrm{~b})$ & $92.30(85.40-100.30)$ \\
\hline $\mathrm{MCV}(\mathrm{fL})$ & $92.00(90.00-94.00)$ & $95.80(92.48-98.08) *$ & $28.97 \pm 3.73 \S$ \\
\hline $\mathrm{MCH}(\mathrm{pg})$ & $29.83 \pm 1.39$ & $31.29 \pm 1.53 \mathrm{~b})$ & $30.85 \pm 2.35 * \S$ \\
\hline $\mathrm{MCHC}(\mathrm{g} / \mathrm{dL})$ & $32.48 \pm 0.58$ & $33.16 \pm 1.77$ & $17.32 \pm 2.83 * \S$ \\
\hline $\mathrm{RDW}(\%)$ & $12.79 \pm 0.52$ & $55.12 \pm 30.98 *$ & $67.14 \pm 31.06 *$ \\
\hline Reticulocytes $(\mathrm{x} 10 \% / \mathrm{L})$ & $33.57 \pm 22.78$ & $1.08(0.72-1.51) *$ & $0.92(0.52-1.24) *$ \\
\hline $\mathrm{RPI}$ & $0.42(0.19-0.66)$ & $0.61 \pm 0.23$ & $0.62 \pm 0.24$ \\
\hline Bilirubin $(\mathrm{mg} / \mathrm{dL})$ & $0.62 \pm 0.25$ & & \\
\hline
\end{tabular}

* $p<0.05, v s$ controls; $\S p<0.05 v s$ responders.

$\mathrm{Hb}$ : haemoglobin concentration; RBC: red blood cell count; MCV: mean cell volume; MCH: mean cell haemoglobin; MCHC: mean cell haemoglobin concentration; RDW: red blood cell distribution width; RPI: reticulocyte production indice. Results are presented as mean \pm standard deviation or as median (interquartile ranges).

Analysing the results for the studied parameters, before and immediately after the dialysis procedure, in 20 of the studied CKD patients, we found a statistically significant rise in $\mathrm{Hb}$ [12.10 (10.95-12.80 g/dL) vs 13.20 (11.15-14.60 $\mathrm{g} / \mathrm{dL}), p<0.05]$ and significant decreases in $\mathrm{MBH}[75.00$ $\left(49.00-109.50 \times 10^{-4} \%\right)$ vs $24.50 \quad\left(13.00-64.50 \times 10^{-4} \%\right)$, $p<0.05]$, in plasma TBA $\left(1.52 \pm 0.30 \times 10^{-3} \mathrm{mmol} / \mathrm{L} v s 1.36 \pm\right.$ $\left.0.26 \times 10^{-3} \mathrm{mmol} / \mathrm{L}, p<0.05\right)$ and in plasma TAS $(1.58 \pm 0.38$ $\mathrm{mmol} / \mathrm{L} v s 1.26 \pm 0.35 \mathrm{mmol} / \mathrm{L}, p<0.05)$ after haemodialysis. The other studied parameters remain unchanged after haemodialysis. No statistically significant differences were found between responders and non-responders patients, for the studied changes after the haemodialysis procedure. 
Table 2. RBC Damage, Enzymatic Activities of Erythrocyte SOD and GPx, Plasma Lipid Peroxidation, Antioxidant Status and CRP, for Controls and CKD Patients

\begin{tabular}{|c|c|c|c|}
\hline & $\begin{array}{c}\text { Controls } \\
(\mathbf{n = 2 6})\end{array}$ & $\begin{array}{c}\text { Responders } \\
(\mathbf{n}=\mathbf{3 2})\end{array}$ & $\begin{array}{c}\text { Non-Responders } \\
(\mathbf{n}=\mathbf{3 1})\end{array}$ \\
\hline \hline HMWAg (\%) & $19.90(15.42-21.12)$ & $14.86(11.30-20.19) *$ & $15.92(14.28-18.68) *$ \\
\hline Band 3 monomer (\%) & $55.28(53.39-57.41)$ & $61.26(56.08-65.06) *$ & $21.34 \pm 5.78 * \S$ \\
\hline Pfrag (\%) & $26.29 \pm 4.78$ & $24.01 \pm 6.03$ & $0.27 \pm 0.06 *$ \\
\hline HMWAg/ Band 3 monomer & $0.33 \pm 0.07$ & $0.26 \pm 0.09 *$ & $0.35 \pm 0.13 * \S$ \\
\hline Pfrag/ Band 3 monomer & $0.48 \pm 0.11$ & $0.41 \pm 0.14 *$ & $58.50(30.50-100.75)$ \\
\hline MBH (x10 $\%)$ & $53.00(37.75-89.75)$ & $45.50(25.25-80.75)$ & $43.11 \pm 13.87$ \\
\hline GPx (IU/g Hb) & $35.62 \pm 8.83$ & $48.73 \pm 13.46 *$ & $1074.76(581.6-2638.7)$ \\
\hline SOD (IU/g Hb) & $1039.8(737.4-1331.6)$ & $858.97(662.4-1256.5)$ & $1.48 \pm 0.30 *$ \\
\hline TBA (x10-3 mmol/L) & $0.84 \pm 0.27$ & $1.49 \pm 0.32 *$ & $1.76 \pm 0.24 *$ \\
\hline TAS (mmol/L) & $1.41 \pm 0.29$ & $1.81 \pm 0.24 *$ & $0.86 \pm 0.18 *$ \\
\hline TBA/TAS & $0.60 \pm 0.28$ & $0.83 \pm 0.18 *$ & $10.14(3.82-38.99) * \S$ \\
\hline CRP (mg/dL) & $1.75(0.76-4.70)$ & $3.20(1.73-7.23) *$ & $*$ \\
\hline
\end{tabular}

$* p<0.05, v s$ controls; $\S p<0.05$ vs responders.

HMWAg; high molecular weight aggregates; Pfrag: proteolytic fragments; SOD: superoxide dismutase; GPx: glutathione peroxidase; MBH: membrane bound haemoglobin; TAS: total antioxidant status; TBA: plasma lipid peroxidation; CRP: C-reactive protein

Results are presented as mean \pm standard deviation or as median (interquartile ranges).

We found similar statistical differences between groups when CKD patients with diabetic nephropathy were removed from the analyses, to exclude diabetes as a confounding factor (as previously referred). Actually, the values that we found for CKD patients, with and without diabetic nephropathy, were very similar.

\section{DISCUSSION}

The treatment of anaemia, the most frequent haematological alteration found in CKD patients, has been improved in the last years by rhEPO therapy. This therapy increases RBC production, providing an increased number of younger and more powerful RBCs in terms of functionality. However, it is known that in this kind of patients RBCs have to circulate in an adverse plasma environment and that they have to undergo a haemodialysis procedure regularly. Both conditions may induce metabolical and/or physical RBC damage that may lead to premature senescence and removal of RBCs.

As previously described [1-3], in the present study, despite rhEPO therapy, anaemia was a common finding in our CKD patients under haemodialysis (Table 1). The reduction in $\mathrm{Hb}$ concentration was associated with a statistically significant increase in circulating reticulocytes and RPI (twice the value of controls), reflecting the erythropoietic stimulus triggered by rhEPO therapy. The higher RDW observed in CKD patients, may reflect the rise in reticulocyte count and/or a higher RBC damage, with anisocytosis development.

To evaluate oxidative and proteolytic $\mathrm{RBC}$ damage we evaluated the band 3 profile and $\mathrm{MBH}$. As $\mathrm{Hb}$ denatures, it binds to intracellular surface of the membrane, leading to band 3 aggregation [31]. Previous studies in our lab showed that oxidative stress conditions [16-20] are associated to an increase in band 3 HMWAg and a reduction in Pfrag. Moreover, we have also reported that younger RBCs present a decreased band 3 HMWAg and a rise in Pfrag [17].

We report, for the first time, changes in the erythrocyte membrane band 3 profile in CKD patients. CKD patients presented a decrease in HMWAg and in HMWAg/band 3 monomer ratio. These changes seem to reflect a younger $\mathrm{RBC}$ population. In fact, erythrocyte membranes from younger RBCs are poorer in HMWAg and richer in Pfrag. However, our CKD also presented a decrease in Pfrag and in Pfrag/band 3 monomer ratio, which are associated to a rise in RBC damage. Thus, it seems that the band 3 profile observed in CKD patients is associated both to an increase in younger RBCs and to an increase in damaged RBCs. The same results were previously described to be associated with pregnancy [20].

Haemodialysis patients exhibited higher plasma levels of TBA and also of TAS. A higher TBA/TAS ratio reflecting a higher rise in TBA than in TAS, is in favour of an oxidative stress. No difference between controls and CKD patients was found for RBC SOD activity; this, has been related to an enzymatic inactivation due to hyperproduction of ROS [32]; the increase in RBC GPx activity is probably due to the higher levels of circulating reticulocytes (almost twice the value of controls). Actually, it has been reported that reticulocytes present a higher GPx activity when compared to mature RBCs. Data of about antioxidant RBC enzymes activities in haemodialysis patients are controversial, as authors reported decreased, increased or even unchanged enzyme activities [33-35]. 
The increased erythropoietic stimulation triggered by rhEPO therapy, seems to provide a younger RBC population that has to face an adverse plasma oxidative environment as shown by higher values of plasma lipid peroxidation and by the band 3 profile showing changes denoting a younger but also a damaged RBC population.

Analyzing the haematological results presented by the two groups of CKD patients, responders and non-responders to rhEPO therapy, we found that the non-responders presented anaemia, showing a statistically significant decrease in $\mathrm{Hb}, \mathrm{Ht}$ and $\mathrm{RBC}$ count (Table 1). These changes were associated to significantly lower MCH and MCHC values, showing a hypocromic $\mathrm{RBC}$ change, which was not due to erythropoietic deficiencies in iron, folic acid or vitamin B12 (data not shown). A statistically significant rise in RDW was also observed in non-responders that could reflect reticulocytosis and/or anisocytosis due to a higher RBC damage. As responders and non-responders presented with a similar reticulocyte value, though presenting non-responders a trend to higher reticulocyte count, the increase in RDW seems to mainly result from anisocytosis, reflecting a higher $\mathrm{RBC}$ damage.

Non-responders CKD patients, compared to responders, though presenting a similar reticulocyte and RBC count, showed a decrease in Pfrag and in Pfrag/band 3 monomer ratio, and a trend to higher values of MBH (Table 2), suggesting that they present a higher RBC damage that may result from a more adverse plasma microenvironment. Resistance to rhEPO therapy in CKD patients seems, therefore, to be associated to an increase in RBC damage. No alterations were found in non-responders patients in the parameter related to RBC antioxidant capacity; TAS and TBA.

This study also shows that the haemodialysis procedure per se does not lead to an increase in the studied markers RBC damage. Actually, no differences were found after haemodialysis, in band 3 profile and, besides that, a decrease in MBH, TBA and TAS were observed, probably reflecting the improvement in the plasma environment and/or the removal of damaged RBCs.

It is known that the linkage of denatured $\mathrm{Hb}$ to $\mathrm{RBC}$ membrane at the cytoplasmic pole of the protein band $3 \mathrm{fa}-$ vours the aggregation of this transmembrane protein [36] and turns the cell membrane more rigid. In our study, the MBH decreased after the haemodialysis procedure, suggesting that damaged RBCs may have been removed from circulation. Actually, damaged RBCs may be more susceptible to haemolyse, when submitted to mechanical stress as may occur during haemodialysis. Another possibility is that the small portions of membrane with bound $\mathrm{Hb}$ and band 3 aggregates might be lost by a process of membrane vesiculation, as occurs in splenic sinusoids, where RBCs have also to deform, to go through that microvasculature.

The increased indicators of $\mathrm{RBC}$ damage found in our CKD patients, particularly in non-responders (decrease in Pfrag and a trend to increase of $\mathrm{MBH}$ ), was also associated to an increase in CRP. There are evidences that a rise in proinflammatory cytokines levels (especially interleukine-6) and in the acute phase reactant CRP, are among the most powerful independent predictors of resistance to rhEPO therapy, and are associated with cardiovascular morbidity and mortality in CKD patients [4-7]. There are also some evidence of a bidirectional and synergistic linkage between inflammation and oxidative stress. However, further studies are required targeting specific oxidative pathways, as well as specific inflammatory pathways to elucidate this biological linkage $[6,7]$. The increase RBC damage found in CKD patients, particularly in non-responders, can also be associated to the proteolytic effect of elastase released from neutrophils during haemodialysis procedure. In fact, recently higher plasma levels of elastase were demonstrated by us in nonresponders patients [37].

Our data suggest that CKD patient's present younger RBC population, which could be related to the rhEPO therapy. The adverse plasma environment associated to CKD patients under hemodialysis imposes changes in band 3 profile, particularly in non-responders.

\section{ACKNOWLEDGEMENTS}

We are very grateful to FMC, Dinefro - Diálises e Nefrologia, SA and Uninefro - Sociedade Prestadora de Cuidados Médicos e de Diálise, SA, and to their nurses for the technical support. This study was supported by a $\mathrm{PhD}$ grant (SFRH/BD/27688/2006) attributed to E. Costa by Fundação para a Ciência e Tecnologia and Fundo Social Europeu.

\section{REFERENCES}

[1] Foley, R.N.; Parfrey, P.S.; Sarnak, M.J. Clinical epidemiology of cardiovascular disease in chronic renal failure. Am. J. Kidney. Dis., 1998, 32(suppl. 3), S112-S119.

[2] Foley, R.N.; Parfrey, P.S.; Harnett, J.D.; Kent, G.M.; Murray, D.C.; Barre, P.E. The impact of anemia on cardiomyopathy morbidity and mortality in end-stage renal disease. Am. J. Kidney Dis., 1996, 28, 53-61.

[3] Locatelli, F.; Conte, F.; Marcelli, D. The impact of hematocrit levels and erythropoietin treatment on overall and cardiovascular mortality and morbidity - the experience of the Lombardy dialysis registry. Nephrol. Dial. Transplant., 1998, 13, 1642-1644.

[4] Smrzova, J.; Balla, J.; Bárány, P. Inflammation and resistance to erythropoiesis-stimulting agents-what do we know and what needs to be clarified? Nephrol. Dial. Transplant., 2005, 20(Suppl. 8), viii2-viii7.

[5] Bárány, P. Inflamation, serum C-reactive protein, and erythropoietin resistance. Nephrol. Dial .Transplant, 2001, 16, 224-227.

[6] Spittle, M.A.; Hoenich, N.A.; Handelman, G.J.; Adhikarla, R.; Homel, P.; Levin, N.W. Oxidative stress and inflammation in hemodialysis patients. Am. J.Kidney Dis., 2001, 38, 1408-1413.

[7] Pupim, L.B.; Himmelfarb, J.; McMonagle, E.; Shyr, Y.; Ikizler, T.A. Influence of initiation of maintenance hemodialysis on biomarkers of inflammation and oxidative stress. Kidney International, 2004, 65, 2371-2379.

[8] Sommerburg, O.; Grune, T.; Hampl, H.; Riedel, E.; van Kuijk, F.J.; Ehrich, J.H.H.; Siems, W.G. Does long-term treatment of renal anaemia with recombinant erythropoietin influence oxidative stress in haemodialysed patients? Nephrol. Dial. Transplant., 1998, 13, 2583-2587.

[9] Himmelfarb, J. Linking oxidative stress and inflammation in kidney disease: which is the chicken and which is the egg? Seminars in Dialysis, 2004, 17, 449-454.

[10] Drueke, T.B.; Eckardt, K.U. Role of secondary hyperparathyroidism in erythropoietin resistance of chronic renal failure patients. Nephrol. Dial. Transplant., 2002, 17(suppl 5), 28-31.

[11] Lucchi, L.; Bergamini, S.; Botti, B.; Rapanà, R.; Ciuffreda, A. Ruggiero, P.; Ballestri, M.; Tomasi, A.; Albertazzi, A. Influence of different hemodialysis membrane on red blood cell susceptibility of oxidative stress. Artif. Organs, 2000, 24, 1-6.

[12] Fryer M.J. Vitamin E as a protective antioxidant in progressive renal failure. Nephrology, 2000, 5, 1-7.

[13] Sezer, M.T.; Akin, H.; Demir, M.; Erturk, J.; Aydin, Z.D.; Savik, E.; Tunc, N. The effect of serum albumin levels on iron-induced 
oxidative stress in chronic renal failure patients. J. Nephrol., 2007, 20, 196-203.

[14] Costa, E.; Lima, M.; Alves, J.M.; Rocha, S.; Rocha-Pereira, P.; Castro, E.; Miranda, V.; Sameiro-Faria, M.; Loureiro, A.; Quintanilha, A.; Belo, L.; Santos- Silva, A. Inflammation, T-cell phenotype and inflammatory cytokines in chronic kidney disease patients under haemodialysis and its relationship to resistance to recombinant human erythropoietin therapy. J .Clin. Immunol., 2008, 28, 268-275.

[15] Imanishi, H.; Nakai, T.; Abe, T.; Takino, T. Glutathione-linked enzyme activities in red cell aging. Clin. Chim. Acta., 1986, 159, 73-76.

[16] Rocha-Pereira, P.; Santos-Silva, A.; Rebelo, I.; Figueiredo, A.; Quintanilha, A.; Teixeira, F. Erythrocyte damage in mild and severe psoriasis. Br. J.Dermatol., 2004, 150, 232-244.

[17] Santos-Silva, A.; Castro, E.M.B.; Teixeira, N.A.; Guerra, F.C.; Quintanilha, A. Erythrocyte membrane band 3 profile imposed by cellular aging, by activated neutrophils and by neutrophilic elastase. Clin. Chim . Acta., 1998, 275, 185-196.

[18] Santos-Silva, A.; Castro, E.M.B.; Teixeira, N.A.; Guerra, F.C.; Quintanilha, A. Altered erythrocyte membrane band 3 profile as a marker in patients at risk for cardiovascular disease. Atherosclerosis, 1995, 116, 199-209.

[19] Santos-Silva, A.; Rebelo, I.; Castro, E.M.B.; Belo, L.; Catarino, C.; Monteiro, I.; Almeida, M.D.; Quintanilha, A. Erythrocyte damage and leukocyte activation in ischemic stroke. Clin. Chim. Acta., 2002, 320, 29-35.

[20] Belo, L.; Rebelo, I.; Castro, E.M.B.; Catarino, C.; Pereira-Leite, L.; Quintanilha, A.; Santos-Silva, A. Band 3 as a marker of erythrocyte changes in pregnancy. Eur. J. Haematol., 2002, 69, 145-151.

[21] Locatelli, F.; Aljama, P.; Barany, P.; Canaud, B.; Carrera, F.; Eckardt, K.U.; Horl, W.H.; Macdougal, I.C.; Macleod, A.; Wiecek, A.; Cameron, S. European Best Practice Guidelines Working Group. Revised European best practice guidelines for the management of anaemia in patients with chronic renal failure. Nephrol. Dial. Transplant., 2004, 19 [Suppl 2], ii1-ii47.

[22] Hillman, R.S.; Ault, K.A. Clinical approach to anemia In: Hematology in Clinical Practice, McGraw-Hill: New-York, 2002.

[23] Niehaus, W.G.; Samuelsson, B. Formation of malonaldehyde from phospholipids arachidonate during microsomal lipid peroxidation. Eur. J.Biochem., 1968, 6, 126-130.

[24] Dodge, J.T.; Mitchell, C.; Hanahan, D.J. The preparation and chemical characteristics of hemoglobin-free ghosts of human erythrocytes. Arch. Biochem . Biophys., 1963, 100, 119-130.
[25] Bradford, M.M. A rapid and sensitive method for the quantitation of microgram quantities of protein utilizing the principle of proteindye binding. Anal. Biochem., 1976, 72, 248-254.

[26] Laemmli U.K. Cleavage of structural proteins during the assembly of the head of bacteriophage T4. Nature, 1970, 227, 680-685.

[27] Towbin, H.; Staehelin, T.; Gordon, J. Electrophoretic transfer of proteins from polyacrylamide gels to nitrocellulose sheets: procedure and some applications. Proc. Natl. Acad. Sci., USA, 1979, 76, 4350-4354.

[28] Czerwinski, M.; Wasniowska, K.; Steuden, I.; Duk, M.; Wiedlocha, A.; Lisowska, E. Degradation of the human erythrocyte membrane band 3 studied with monoclonal antibody directed against an epitope on the cytoplasmic fragment of band 3. Eur. J. Biochem., 1988, 174, 647-654.

[29] Philips, M.; Cataneo, R.N.; Cheema, T.; Greenberg, J. Increased breath biomarkers of oxidative stress in diabetes mellitus. Clin. Chim. Acta., 2004, 344, 189-194.

[30] Maritim, A.C.; Sanders, R.A.; Watkins, J.B. Diabetes, oxidative stress, and antioxidants: a review. J. Biochem. Mol. Toxicol., 2003, 17, 24-38.

[31] Lutz, H.U. Naturally occurring anti-band 3 antibodies. Transfus. Med. Rev., 1992, 6, 201-211.

[32] Delmas-Beauvieux, M.C.; Combe, C.; Peuchant, E.; Carbonneau, M.A.; Dubourg, L.; de Précigout, V.; Aparicio, M.; Clerc, M. Evaluation of red blood cell lipoperoxidation in hemodialysed patients during erythropoietin therapy supplemented or not with iron. Nephron, 1995, 69, 404-410.

[33] Chen, C.K.; Liaw, J.M.; Juang, J.G.; Lin, T.H. Antioxidant enzymes and trace elements in hemodialyzed patients. Biol. Trace. Elem. Res., 1997, 58, 149-157.

[34] Túri, S.; Németh, I.; Vargha, I.; Matkovics, B.; Dobos, E. Erythrocyte defense mechanisms against free oxygen radicals in haemodialysed uraemic children. Pediatr. Nephrol., 1991, 5, 179-183.

[35] Paul, J.L.; Sall, N.D.; Soni, T.; Poignet, J.L.; Lindenbaum, A.; Man, N.K.; Moatti, N.; Raichvarg, D. Lipid peroxidation abnormalities in hemodialyzed patients. Nephron, 1993, 64, 106-109.

[36] Low, P.S. Role of hemoglobin desnaturation and band 3 clustering in initiating red cell removal. In: Red Blood Cell Aging, Plenum Press:New York, 1991.

[37] Costa, E.; Rocha, S.; Rocha-Pereira, P.; Nascimento, H.; Castro, E.; Miranda, V.; Sameiro-Faria, M.; Loureiro, A.; Quintanilha, A.; Belo, L.; Santos-Silva, A. Neutrophil Activation and Resistance to Recombinant Human Erythropoietin Therapy in Hemodialysis Patients. Am. J. Nephrol., 2008, 28, 935-940.

(C) Costa et al.; Licensee Bentham Open .

This is an open access article licensed under the terms of the Creative Commons Attribution Non-Commercial License (http://creativecommons.org/licenses/ by-nc/3.0/) which permits unrestricted, non-commercial use, distribution and reproduction in any medium, provided the work is properly cited. 